\title{
MMP Inhibitor S-3304
}

National Cancer Institute

\section{Source}

National Cancer Institute. MMP Inhibitor S-3304. NCI Thesaurus. Code C2671.

An orally-agent agent with potential antineoplastic activity. S-3304 inhibits matrix metalloproteinases (MMPs), thereby inducing extracellular matrix degradation, and inhibiting angiogenesis, tumor growth and invasion, and metastasis. ( $\mathrm{NCIO4)}$ 